Cerebrovasc Dis 2006;22:215

DOI: $10.1159 / 000093958$

\section{Long-Term Outcome in Patients with Cervical- Artery Dissections: There Is Still a Lot to Know}

\author{
Didier Leys, Stéphanie Debette \\ Department of Neurology, Stroke Department, \\ Lille University Hospital, Lille, France
}

Cervical-artery dissection (CAD) has been increasingly recognized over the last 20 years with the development of noninvasive techniques [1] and is now the leading cause of ischemic stroke in young patients in western countries [2]. In this issue, the study of Arauz et al. [3] provides another evidence that the risk of recurrence of ischemic stroke is likely to be low: of 126 survivors with a median follow-up of 19 months, only 6 had a recurrent ischemic stroke without recurrent dissection, while 17 had had a first ischemic event within 8 days before the index event that led to the diagnosis of dissection. This result confirms that of the previous studies (see list and details in Leys et al. [1]).

Arauz et al. [3] emphasize the lack of difference in outcome between patients who received antiplatelet agents and those who received anticoagulation. This is not surprising with such a low event rate and statistical power. Moreover, in the absence of randomized allocation of treatments, no conclusion would have been possible with this study design.

This study [3] provides however two other results which are, in our opinion, more interesting and may lead to a practical clinical message: (i) the $6(4.8 \%)$ recurrent ischemic strokes occurred within the first 2 weeks after the index ischemic stroke, and 17 (13.5\%) were preceded by a first event in the previous week, suggesting that the risk is mainly present in the first days after the first-ever ischemic event and may be of approximately 18\%; (ii) recurrences tended to be more frequent in patients with internal-carotid-artery dissections than in those with vertebral-artery dissections ( 5 of 58 vs. 1 of 72). If they are confirmed in prospectively conducted studies, these 2 findings may provide important clues for the selection of patients who may benefit from more 'aggressive' prevention.

However, several questions concerning the outcome of CAD patients should still be answered. What is the most appropriate end point in follow-up studies conducted in CAD patients? Several studies used recurrence of CAD or lack of complete morphological recovery as end points, but we do not feel they are appropriate unless they are accompanied by an ischemic stroke. Accordingly, transient ischemic attacks, especially with the new definition assuming there is no cerebral lesion left, are not appropriate end points, as it does not make sense to use a potentially dangerous treatment to prevent a transient phenomenon, which is not associated with clinical or morphological sequelae.

There is still a lot to know on what really happens years after CAD: (i) previous studies had a retrospective design; therefore, a loss of information is possible, and the quality of the data may be weak for minor strokes, transient ischemic attacks or residual headache; (ii) almost all studies have been conducted by neurologists, explaining why 3 types of CAD patients were probably not included in all studies, i.e. very severe cases leading to early death before the diagnosis was ascertained, cases revealed by isolated pain or cranial nerve palsies who are not always admitted in stroke units and very benign cases that may be frequent and underdiagnosed; (iii) the median duration of follow-up was 3 years which is a short period of time compared with the life expectancy of these patients.

Are late recurrences possible? Can atheroma develop 10 or 15 years later at the site of a residual stenosis? What is the frequency of residual headache or cervical pain? What is the quality of life of patients who completely recovered and have a modified Rankin scale score of 0 ? Until these questions are answered, it is wise to consider that the 3-year rate of recurrence in survivors of ischemic events due to CAD is very low and that stroke recurrence is an issue only during the first 2 weeks. This makes a randomized controlled trial difficult. If anticoagulation is given, there is no reason to continue for more than a few weeks. Even if this may appear provocative, we can even discuss the usefulness of the morphological follow-up of the dissected artery in routine therapy, except for research, as the event rate is very low despite a lack of complete recanalization: in the study of Arauz et al. [3], 86\% of patients with dissections of the internal carotid artery and $64 \%$ of patients with vertebral-artery dissections did not completely recover a normal artery, but recurrences were very rare and none of them occurred more than 2 weeks after the event. A systematic followup of the vascular lesions may induce anxiety both in patients and physicians and lead to inappropriate treatments. For instance, interventional radiological procedures may be performed for a residual aneurysm discovered months or years after CAD, although many of them heal spontaneously over time [4].

A better knowledge of the natural history of CAD is therefore necessary. Previous retrospective studies such as that of Arauz et al. [3] provide important information to design a prospective study on the long-term outcome of this condition.

\section{References}

1 Leys D, Debette S, Lucas C, Leclerc X: Cervical-artery dissections; in Bogousslavsky J, Fisher M (eds): Handbook of Clinical Neurology (Stroke). In press.

2 Leys D, Bandu L, Henon H, Lucas C, Mounier-Vehier F, Rondepierre P, Godefroy O: Clinical outcome in 287 consecutive young adults (15-45 years) with ischemic stroke. Neurology 2002;59:26-33.

3 Arauz A, Hoyos L, Espinoza C, Cantù C, Barinagarrementeria F, Romàn G: Dissection of cervical arteries: long-term follow-up study of 130 consecutive cases. Cerebrovasc Dis 2006;22:150-154.

4 Touze E, Randoux B, Meary E, Arquizan C, Meder JF, Mas JL: Aneurysmal forms of cervical artery dissection: associated factors and outcome. Stroke 2001;32:418-423.

D. Leys

Department of Neurology (EA2691), Lille University Hospital FR-59037 Lille (France)

Tel. +33 3204468 13, Fax +33 3204460 28, E-Mail dleys@chru-lille.fr

\section{KARGER}

Fax +41 613061234 E-Mail karger@karger.ch www.karger.com
(C) 2006 S. Karger AG, Basel

1015-9770/06/0223-0215\$23.50/0

Accessible online at:

www.karger.com/ced 